苗

SSCL-Preprint-160

October 1992

Distribution Category: 414

E. Wang

M. Botlo

J. Dorenbosch

S. Walbran

\title{
Trigger and DAQ Issues in Low-Mass Higgs Searches
}

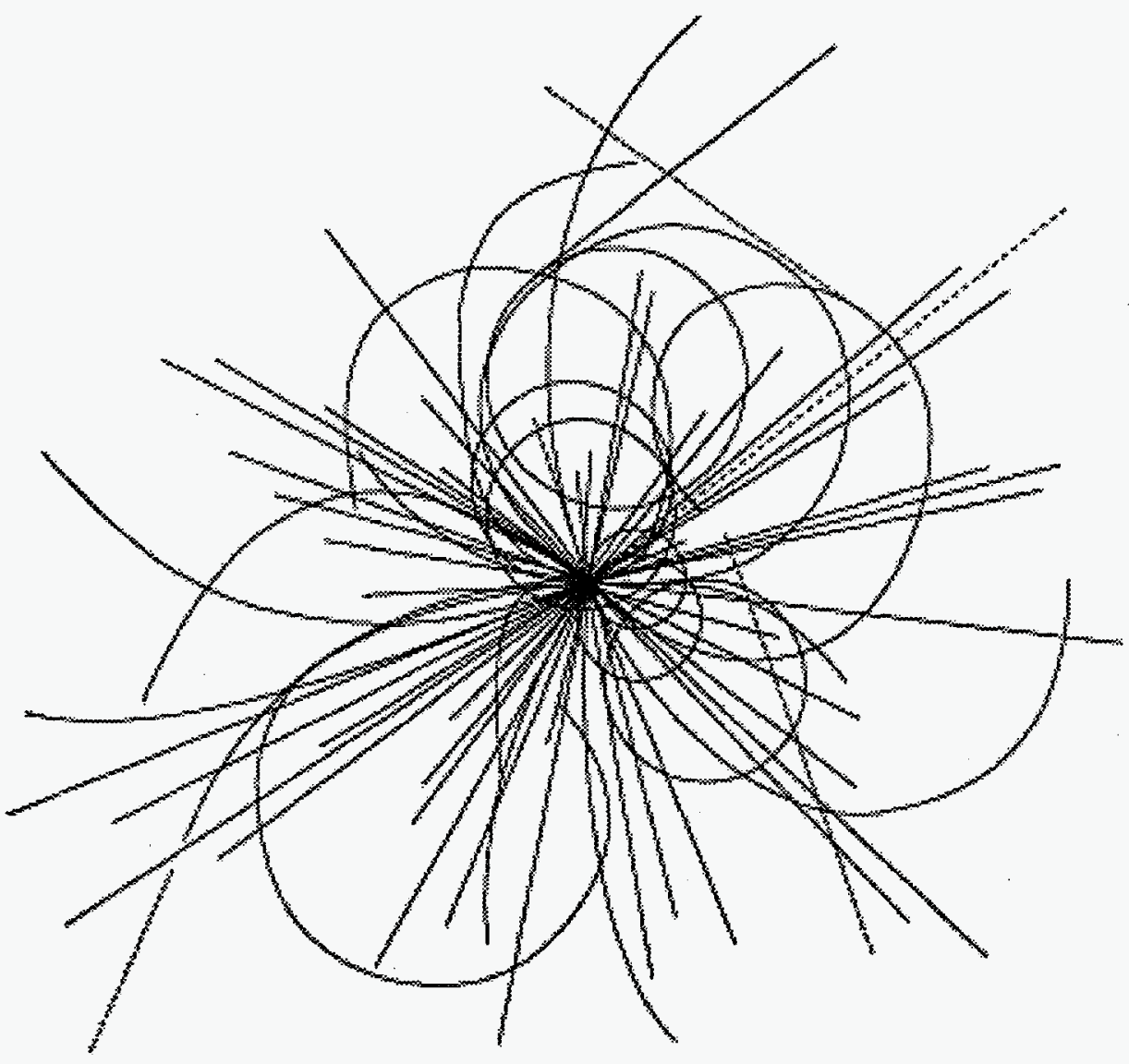

\section{Superconducting Super Collider Laboratory}

APPROVED FOR RELLASEOR PUBLICATION - OR. PATENT GROUP BY. E. . . . . NATF $4 / 3 / 25$ 


\section{Disclaimer Notice}

This report was prepared as an account of work sponsored by an agency of the United States Government. Neither the United States Government or any agency thereof, nor any of their employees, makes any warranty, express or implied, or assumes any legal liability or responsibility for the accuracy, completeness, or usefuiness of any information, apparatus, product, or process disclosed, or represents that its use would not infringe privately owned rights. Reference herein to any specific commercial product, process, or service by trade name, trademark, manutacturer, or otherwise, does not necessarily constitute or imply its endorsement, recommendation, or favoring by the United States Government or any agency thereof. The views and opinions of authors expressed herein do not necessarily state or reflect those of the United States Government or any agency thereot. 
SSCL-Preprint-160

\title{
Trigger and DAQ Issues in Low-Mass Higgs Searches
}

\author{
E. Wang, M. Botlo, J. Dorenbosch, S. Walbran
}

\author{
Superconducting Super Collider Laboratory* \\ 2550 Beckleymeade Ave. \\ Dallas, TX 75237
}

October 1992

\section{DISCLAIMER}

This report was prepared as an account of work sponsored by an agency of the United States Government. Neither the United States Government nor any agency thereof, nor any of their employees, makes any warranty, express or implied, or assumes any legal liability or responsibility for the accuracy, completeness, or usefulness of any information, apparatus, product, or process disclosed, or represents that its use would not infringe privately owned rights. Reference herein to any specific commercial product, process, or service by trade name, trademark, manufacturer, or otherwise does not necessarily constitute or imply its endorsement, recommendation, or favoring by the United States Government or any agency thereof. The views and opinions of authors expressed herein do not necessarily state or reflect those of the United States Government or any agency thereof.

*Operated by the Universities Research Association, Inc., for the U.S. Department of Energy under Contract No. DE-AC35-89ER40486. 


\section{DISCLAIMER}

Portions of this document may be illegible in electronic image products. Images are produced from the best available original document. 


\title{
TRIGGER AND DAQ ISSUES IN LOW-MASS HIGGS SEARCHES
}

\author{
E. M. WANG, M. BOTLO, J. DORENBOSCH, S. WALBRAN \\ Superconducting Super Collider Laboratory* \\ 2550 Beckleymeade Avenue \\ Dallas, TX 75237, USA
}

\begin{abstract}
Results from ongoing trigger and DAQ studies at the Superconducting Super Collider Laboratory are presented. Specific Higgs decay modes are identified, calorimetric triggering algorithms are examined, and implications for data acquisition are discussed.
\end{abstract}

\section{Physics Processes}

Much attention has been paid to detector requirements for Higgs searches at the Superconducting Super Collider (SSC). It is expected that the low-mass (M $\sim 80 \mathrm{GeV}$ ) Higgs searches will define the minimum thresholds and hence the trigger rates. The following modes have been considered in varying amounts of detail over many SSC physics workshops: $:^{1,2}$

1. $W+H \rightarrow l v+b b$

2. $H \rightarrow \tau \tau$

3. $H \rightarrow \gamma$

4. $H \rightarrow Z Z * \rightarrow 4$ or $2 e 2 \mu$.

For the first process, one has to trigger on a single lepton to tag the $W$. For the second process, one must trigger on two stiff tracks. The third process requires one to trigger on one or two gammas. In the last process, one can trigger on one or two electrons (or one or two muons). The most difficult process is no. 2; the next most difficult is no. 3. We shall consider only no. 3 presently. The real problem of triggering at the SSC is that we must retain trigger energy thresholds at levels similar to those used at the Fermilab Tevatron $(\sim 20 \mathrm{GeV})$ while enduring luminosities 1000 times greater!

\footnotetext{
*Operated by the Universities Research Association, Inc., for the U.S. Department of Energy under Contract No. DE-AC35-89ER40486.
} 


\section{Simulation Description}

In the present study, we generate physics events of interest using PYTHIA5.6/JETSET7 $.3,{ }^{3}$ propagate the particles in a geometry $\left(\mathrm{GEM}^{4}\right)$ within GEANT $3.15,{ }^{5}$ and deposit energy spatially using a spot-throwing algorithm. Figure 1 shows the geometry. The main features are listed in Table 1.

TABLE 1. GEM GEOMETRY.

\begin{tabular}{|l|c|c|c|}
\hline & Segmentation & Thickness & Resolution \\
\cline { 2 - 4 } Electromagnetic & $0.032 \times 0.032$ & $25 \mathrm{X}_{0}$ & $0.07 / \sqrt{\mathrm{E}+0.005}$ \\
Hadron & $0.08 \times 0.08$ & $10-11 \lambda$ & $0.6 / \sqrt{\mathrm{E}}+0.01$ \\
\hline
\end{tabular}

Pileup effects are included using a shaping function that is +1 for the first bucket and $-1 / 2$ for the subsequent two buckets. Thus earlier buckets can contribute (with negative values) to a given bucket of interest. Electronic noise is ignored in the present study.

In this study, we make extensive use of fast simulation of electromagnetic (EM) and hadron (HAD) showers. The parametrizations of EM and HAD showers were adapted from $\mathrm{CDF}^{6}$ test beam data. Longitudinal and transverse shape fluctuations are included. The transverse shape ${ }^{7}$ for hadron showers was parametrized from FLUKA ${ }^{8}$ calculations and contains depth dependence. Comparisons were made between full-simulation GEANT with different particle energy cutoffs (the energies where electron, gamma, and hadron showering is stopped) and the parametrization by looking at the fraction of incident energy seen in the hadron compartment of a calorimeter with a 1-interaction-length EM compartment followed by a 10 -interaction-length hadron compartment for $50-\mathrm{GeV}$ charged pions. This is shown in Figure 2. Thus even a full simulation can be tuned via changes in the cutoffs.

If we take cuts where the energy in the hadron compartment is about $10 \%$ of incident energy, then the parametrization gives an answer that is a factor of two or so worse than a full simulation with low cutoffs. In this case, estimates of rejection are expected to be pessimistic, so we will live with this error.
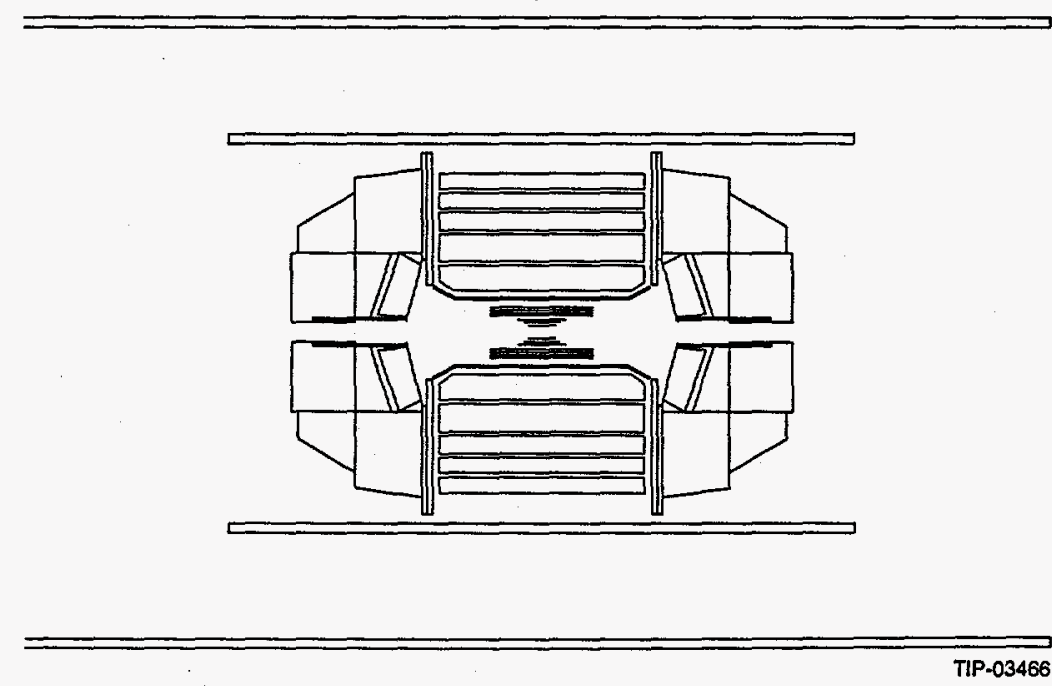

Figure 1. GEM Geometry in This Study. 

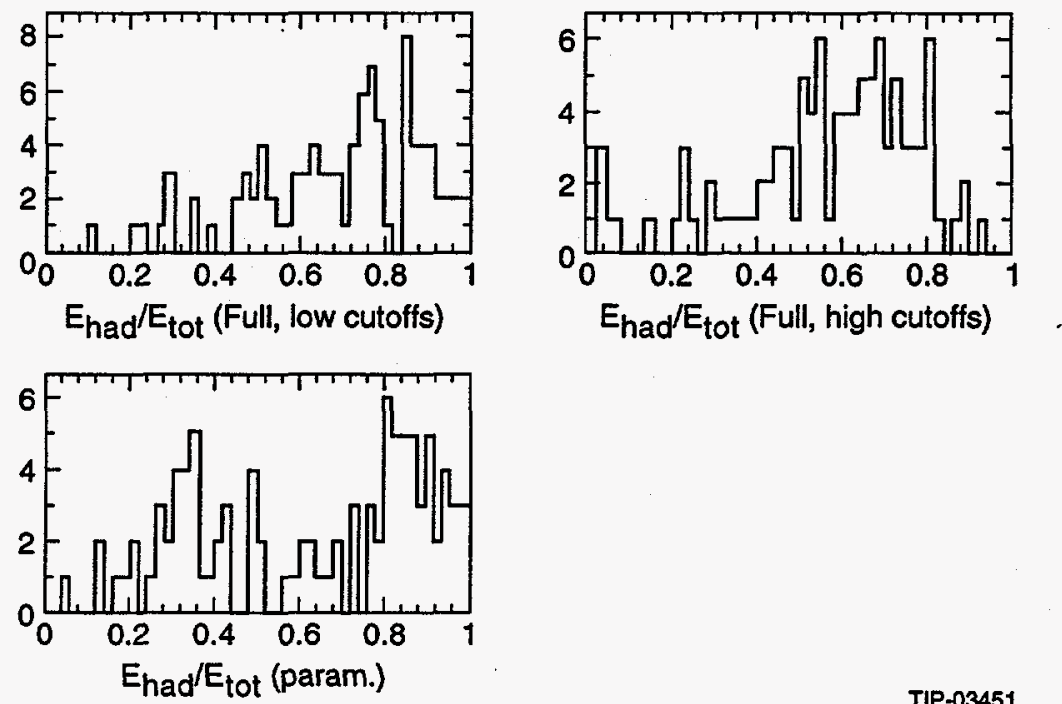

TIP-03451

Figure 2. Check of Longitudinal Shower Fluctuations: $E_{\text {had }} / \mathrm{E}_{\text {tot }}$ for Incident $50 \mathrm{GeV} \pi^{+}$.

(a) GEANT full simulation with low cutoffs ( $100 \mathrm{KeV} \gamma, 1 \mathrm{MeV}$ other) (b) GEANT

full simulation with high cutoffs ( $100 \mathrm{MeV}$ all), and (c) parametrized shower.

\section{Trigger Algorithm}

In triggering, we are basically interested in signal efficiency and trigger rate (background rejection). In this study, we examine a trigger strategy based on two successive levels of cuts: a first level based on coarse-grain calorimeter information using EM and Hadron compartments, and a more complex second-level cut based on full-grained calorimeter EM information.

\subsection{Level 1}

The calorimeter is tiled by non-overlapped coarse trigger towers made up of $5 \times 5$ EM cells summed and $2 \times 2$ Had cells just behind the EM compartment ${ }^{9}$ (Figure 3 ). At the first level, one constructs using these coarse trigger towers:

- ET, EM

- Longitudinal isolation $=\mathrm{E}_{\mathrm{T}, \mathrm{Had}} /\left(\mathrm{E}_{\mathrm{T}, \mathrm{Had}}+\mathrm{E}_{\mathrm{T}, \mathrm{EM}}\right)$.

The plot of the highest $\mathrm{E}_{\mathrm{T}}, \mathrm{EM}$ and second-highest $\mathrm{E}_{\mathrm{T}} \mathrm{EM}$ is shown in Figure 4 for the Higgs and in Figure 5 for two-jet QCD events. Clearly, cutting near $20 \mathrm{GeV}$ on the highest $\mathrm{E}_{\mathrm{T}}$ yields a large QCD rate reduction while retaining almost all of the signal. The distributions of the longitudinal isolation for Higgs and QCD are shown in Figure 6. A cut of 0.1 will keep almost all of the signal while rejecting QCD. It should be noted that the longitudinal isolation cut is determined by how noisy the back Hadron compartment is. If it is too noisy, one would be cutting out real events some fraction of the time. This requirement needs further study. The value of 0.1 we have used appears conservative. 


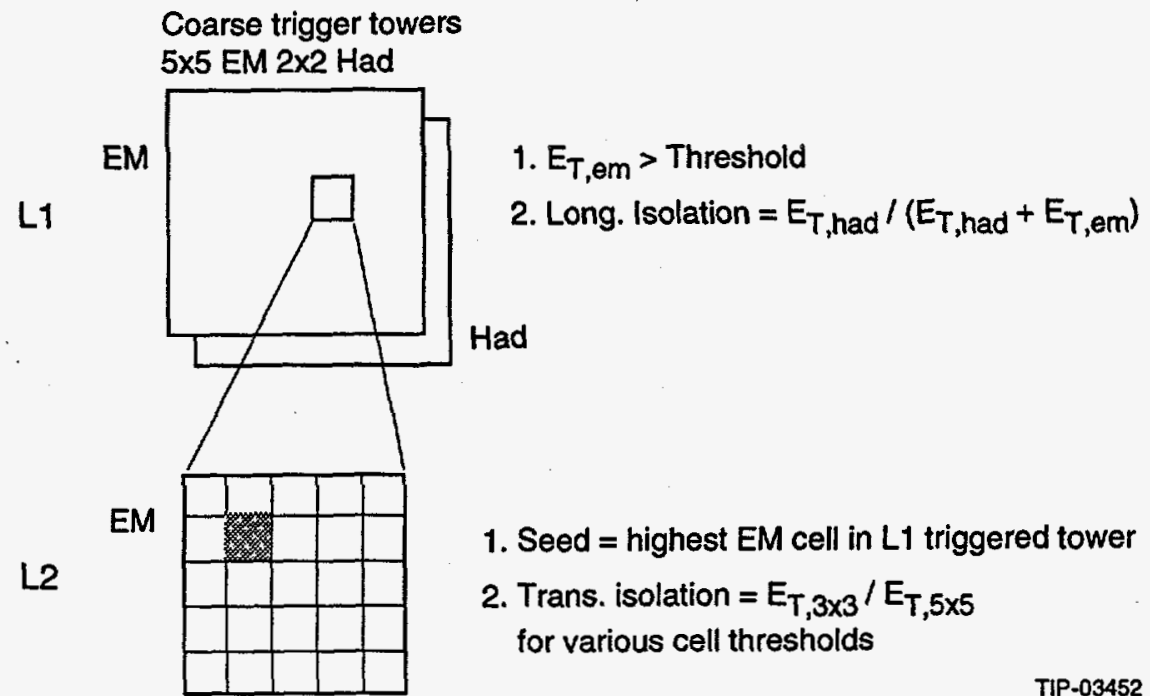

Figure 3. Trigger Algorithms for $\mathrm{L} 1$ and L2.
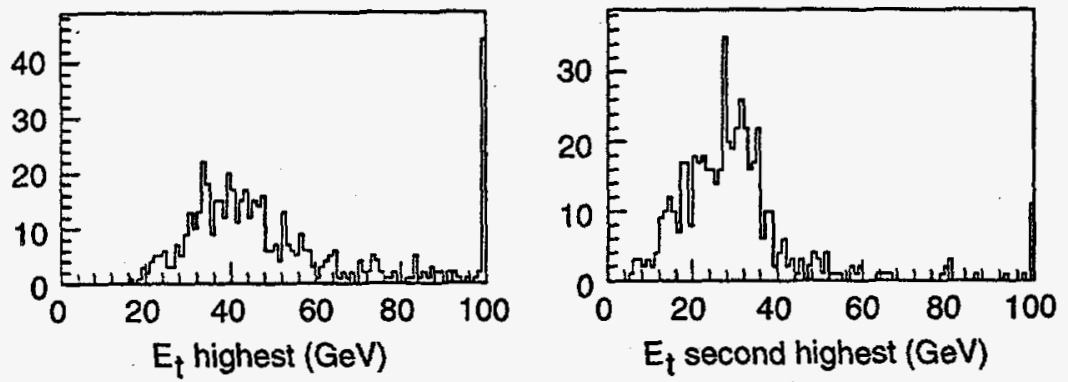

Figure 4. L1 Et Towers for Higgs.
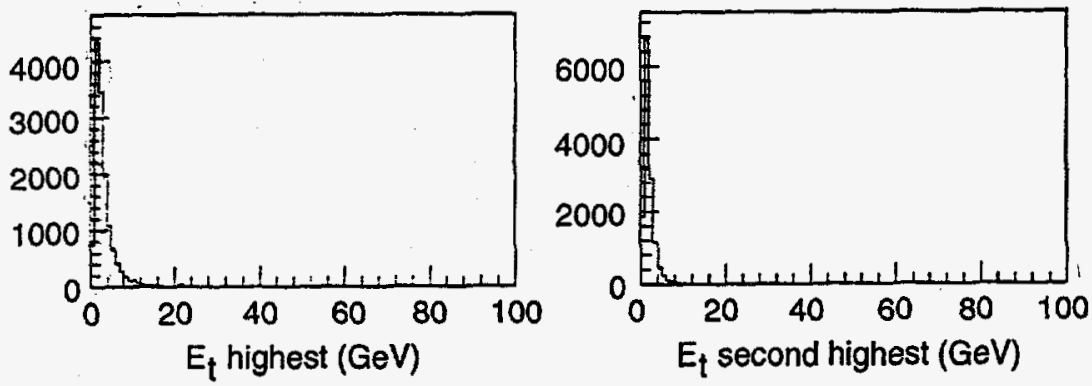

Figure 5. L1 Et Towers for QCD.
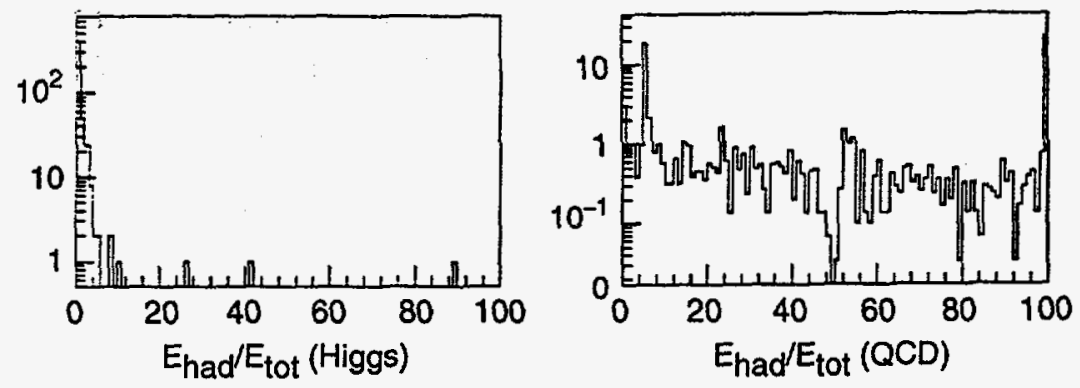

Figure 6. L1 Longitudinal Isolation for Higgs and QCD. 
The trigger phase space showing the QCD trigger rate versus Higgs signal efficiency under threshold cuts and longitudinal isolation cuts is shown in Figure 7. This shows how trigger rate relates to efficiency for a $20-\mathrm{GeV}_{\mathrm{T}}$ cut and how rate and efficiency depend on the $E_{\text {had }} / E_{\text {tot }}$ cut (longitudinal isolation). One can require two EM towers above some threshold and apply longitudinal isolation cuts if need be. The rate is then reduced by more than two orders of magnitude, although the efficiency is starting to suffer. One should note that a geometric efficiency of 0.5 is excluded from all trigger efficiency plots. Thus a 0.7 trigger efficiency has to be combined with 0.5 to yield a net of 0.35 .

(a)

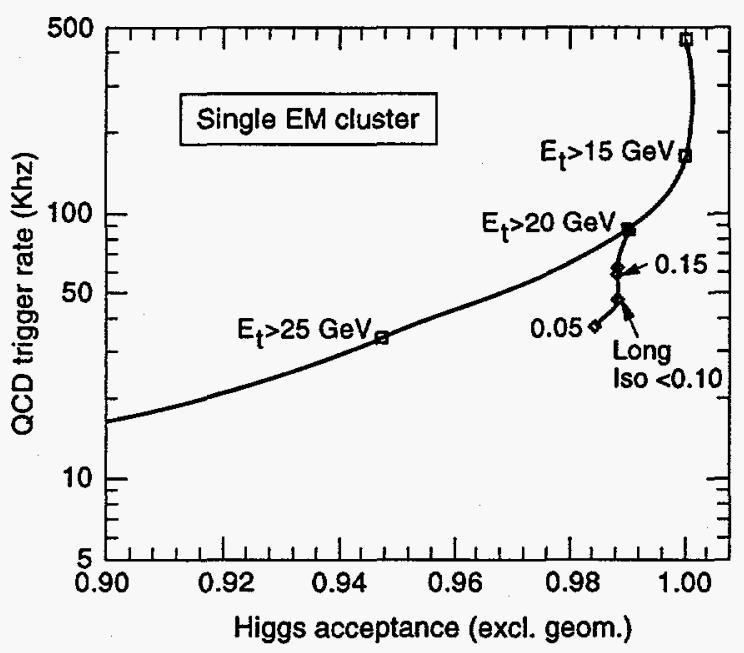

(b)

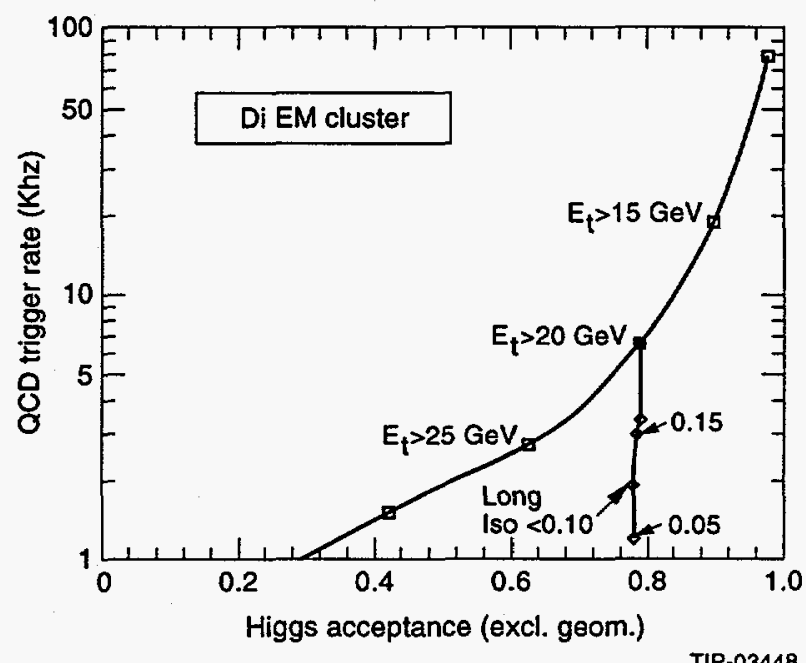

Figure 7. (a) Single EM L1 Trigger Rate vs Higgs Eff. (b) Same as in (a) but for two EM L1 Clusters. Curves show action of ET cut and for given ET cut, action of increased longitudinal isolation.

\subsection{Level 2}

The emphasis of this study centers on the behavior of level-2 triggering under different levels of zero-suppression. We assume that $\mathrm{L} 1$ requirements:

- $\mathrm{E}_{\mathrm{T}, \mathrm{EM}}>20 \mathrm{GeV}$

- longitudinal isolation $<0.1$

have already been imposed. This gives a $50-\mathrm{kHz} \mathrm{L1}$ accept rate (= L2 input). A level-2 algorithm can be defined by going to the highest $\mathrm{L} 1$ coarse-trigger tower and utilizing the full granularity of the EM calorimeter in two steps:

1. find highest EM cell within the L1 coarse tower of interest and define this as a seed cell,

2. construct $\mathrm{E}_{\mathrm{T} 3 \times 3 \mathrm{EM}}, \mathrm{E}_{\mathrm{T} 5 \times 5 \mathrm{EM}}, \mathrm{E}_{\mathrm{T} 7 \times 7 \mathrm{EM}}$, etc., centered on the highest $\mathrm{EM}$ cell found in step 1 where $E_{T 3} \times 3 E_{M}$ is the $E_{T}$ sum of a $3 \times 3$ cell centered on the seed cell. 
We then look at local transverse isolation $=\mathrm{E}_{\mathrm{T} 3 \times 3 \mathrm{EM}} / \mathrm{E}_{\mathrm{T} 5 \times 5 \mathrm{EM}}$. This quantity is equal to 1 for an isolated particle and less than 1 for an unisolated particle. We look at the transverse isolation as a function of calorimeter zero-suppression thresholds of exactly 0 , $100 \mathrm{MeV}, 1 \mathrm{GeV}$, and $5 \mathrm{GeV}$ on individual cells at full granularity. Figure 8 shows the projection of lego plots $\left(E_{T}\right.$ in $\left.[\eta, \phi]\right)$ onto the $\eta$ axis for a QCD L1 accepted event. One sees qualitatively that as one increases the EM cell zero-suppression threshold, the data volume (number of cells above threshold) drops rapidly. The jet activity near the high seed cell,
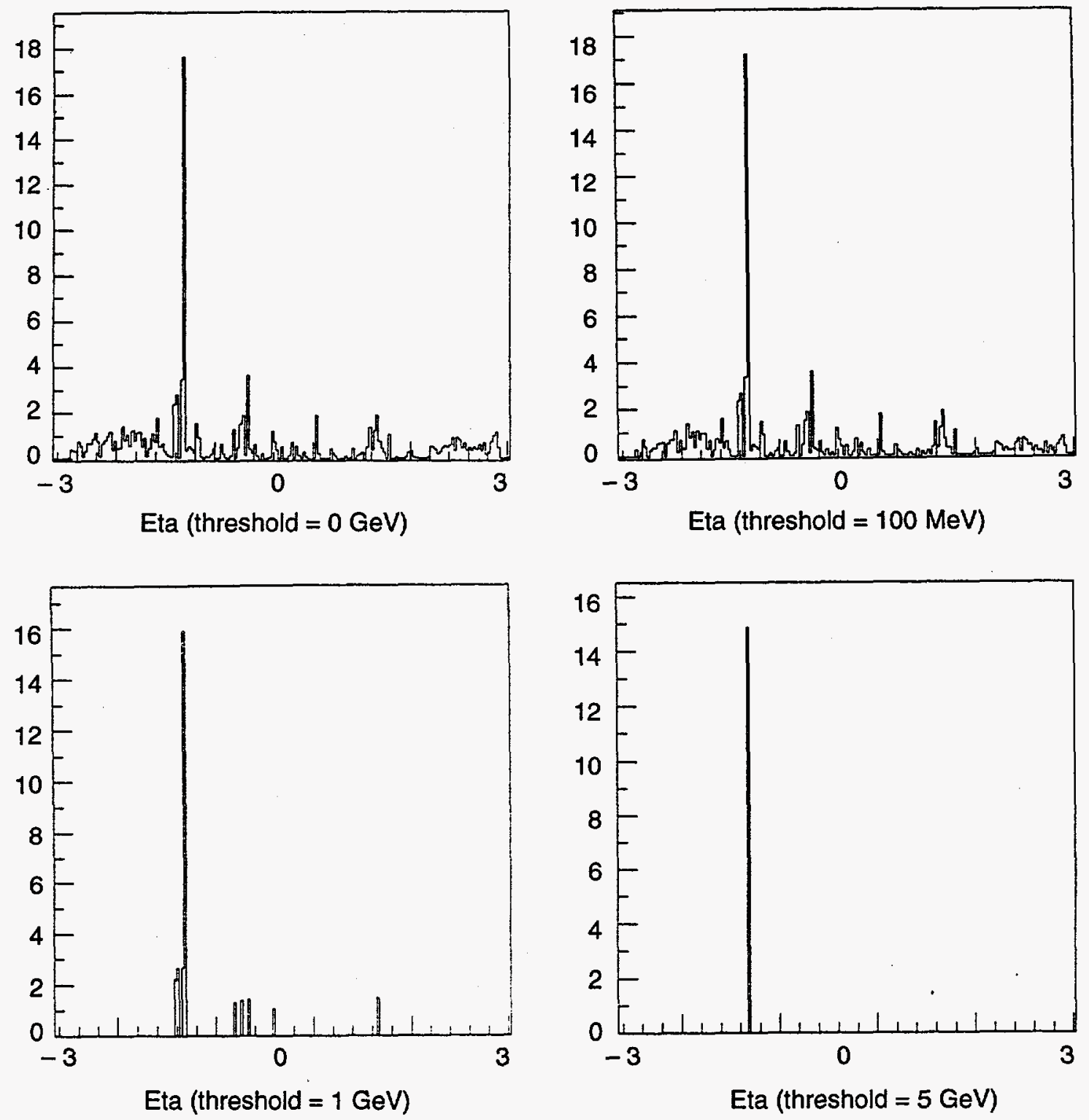

Figure 8. Calorimeter Lego Plots Projected Along $\eta$ Dimension for 0, 0.1, 1.0, and 5.0-GeV EM Cell Thresholds for LI Accepted QCD Event (Input to L2). 
however, remains for cuts up to $1 \mathrm{GeV}$. Figure 9 (top row) shows the behavior of transverse isolation with different zero-suppression thresholds for Higgs events. The middle row shows the corresponding distributions for the QCD events. The bottom row shows the distributions of the number of EM cells above threshold. If we make a transverse isolation cut of 0.9 , we can retain the signal and reject background. Figure 10(a) shows the resulting L2 trigger rate after the transverse isolation cut for different zero-suppression thresholds. Figure 10(b) shows the corresponding efficiencies. Figure 10(c) shows the data volume versus cell thresholds. The product of $\mathrm{L} 1$ accept ( $\mathrm{L} 2$ input) rate and data volume (number of cells above threshold) gives the required L2 input bandwidth (Figure 10(d)). In all plots, the 2 EM cluster rates are also shown. Other level-2 cuts such as wider isolation cones and invariant mass are possible but are not discussed presently.

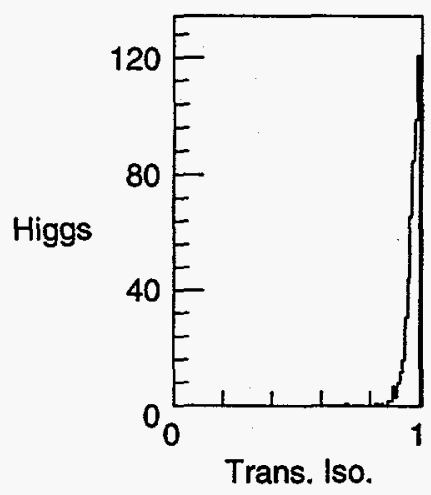

$33 / 550$
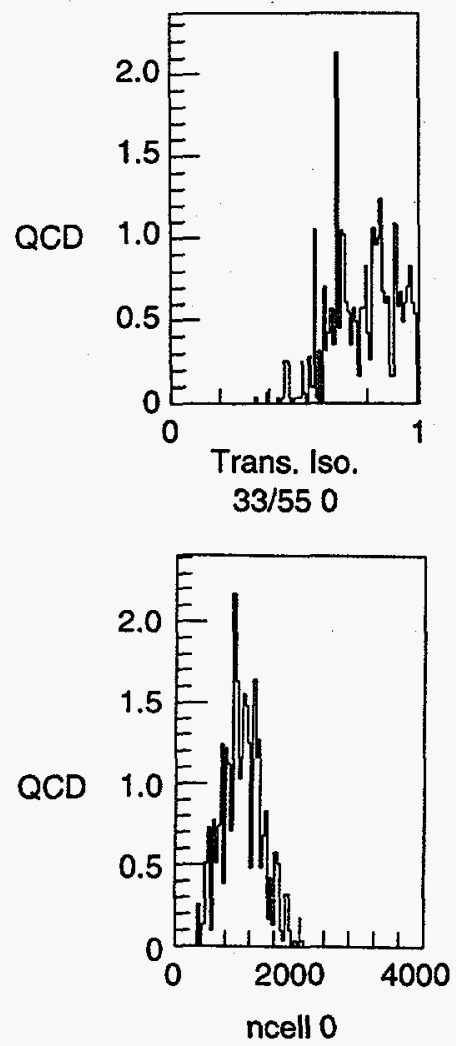

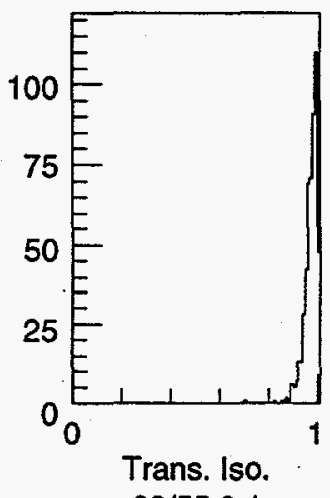

$33 / 550.1$
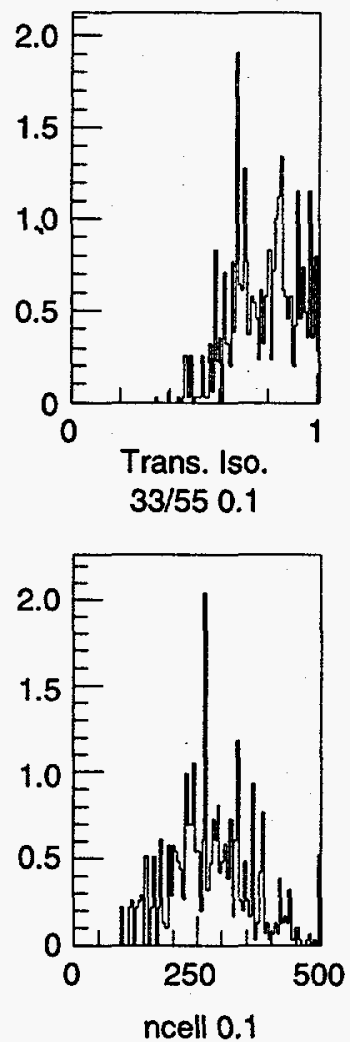
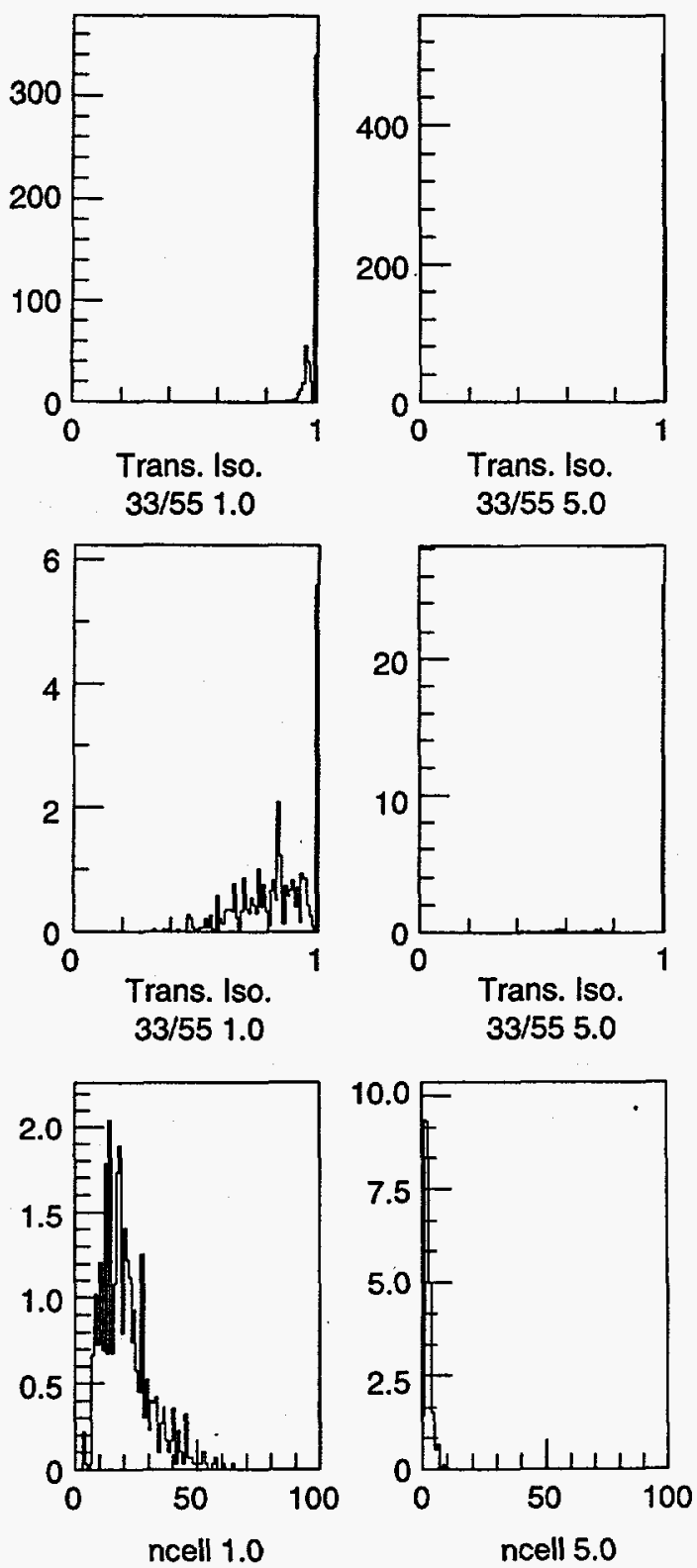

Figure 9. Transverse Isolation $\left(\mathrm{E}_{\mathrm{T} 3 \times 3} / \mathrm{E}_{\mathrm{T} 5} \times 5\right)$ for Higgs (top), $\mathrm{QCD}$ (middle), and Data Volumes (bottom)-number of cells above threshold. 
(a)

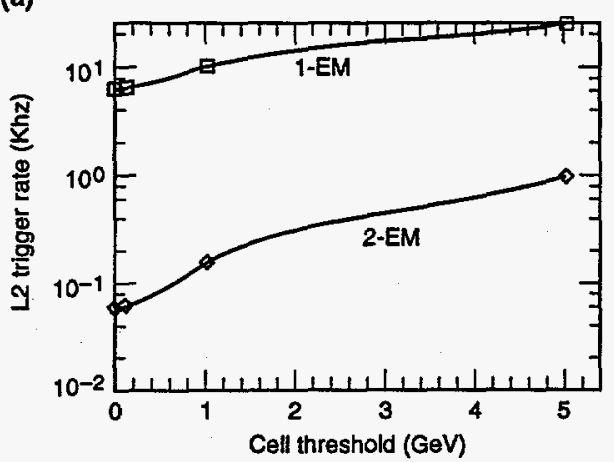

(c)

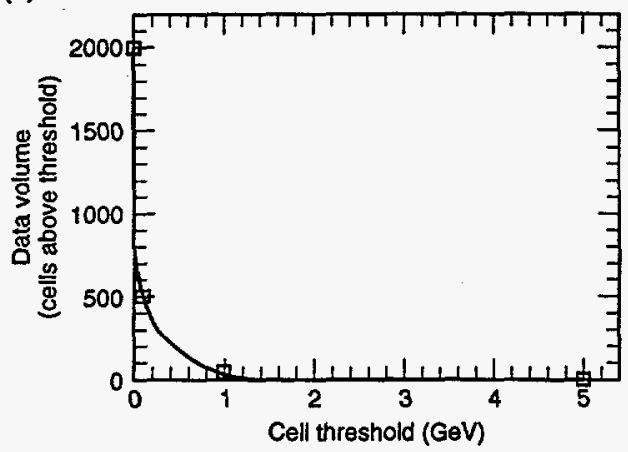

(b)

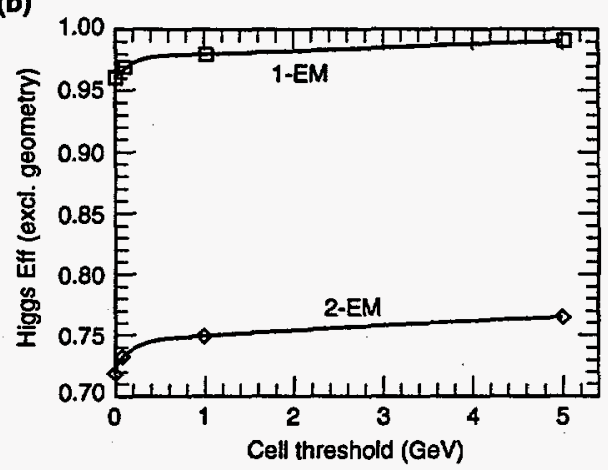

(d)

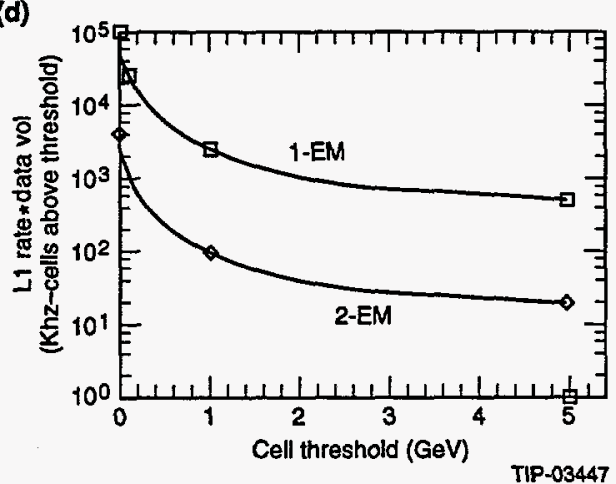

Figure 10. (a) L2 Trigger Rate, (b) L2 Higgs Efficiency, (c) Data Volume, (d) Bandwidth Requirements for Transverse Isolation (as defined in text) $>0.9$.

\section{Implications for DAQ}

Data volumes for the various cell thresholds are shown in Table 2. It is assumed that one has $40 \mathrm{~K}$ (i.e., EM calorimeter only) channels needing 2 bytes for data and 2 bytes for address when using zero-suppression. Table 3 shows some bandwidth requirements for L1-L2 and L2-L3 links coming from the $\mathrm{H} \rightarrow \gamma \gamma$ trigger. Note that after a level-2 accept, a less suppressed data sample is read out. Figure 11 shows a schematic of a trigger/DAQ system designed to take advantage of the data volume reductions possible with zero-suppression.

TABLE 2. DATA VOLUMES FOR CELL THRESHOLDS.

\begin{tabular}{|lrlr|}
\hline EM Calorimeter & $40 \mathrm{~K}$ cells $\times 2$ bytes $/$ cell & $=$ & $80 \mathrm{~Kb}$ \\
$0 \mathrm{GeV}$ & $2 \mathrm{~K}$ cells $\times 4$ bytes $/$ cell & $=$ & $8 \mathrm{~Kb}$ \\
$100 \mathrm{MeV}$ & 500 cells $\times 4$ bytes $/$ cell & $=$ & $2 \mathrm{~Kb}$ \\
$1 \mathrm{GeV}$ & 50 cells $\times 4$ bytes $/$ cell & $=$ & $200 \mathrm{~b}$ \\
\hline
\end{tabular}


TABLE 3. BANDWIDTH REQUIREMENTS.

\begin{tabular}{|c|c|c|c|}
\hline & & $\mathbf{L 1}$ & $\mathbf{L 2}$ \\
\hline \multirow[t]{2}{*}{ Accept Rate (Khz) } & single EM & 50 & 10 \\
\hline & double EM & 7 & 0.1 \\
\hline $\begin{array}{l}\text { Max. Data Volume } \\
\text { (bytes) }\end{array}$ & & $\stackrel{200}{(1 \mathrm{GeV} \text { Thr })}$ & $\begin{array}{c}2000 \\
(0.1 \mathrm{GeV} \text { Thr })\end{array}$ \\
\hline $\begin{array}{l}\text { Max. Bandwidth } \\
\text { Read Out (Mbytes/s) }\end{array}$ & $\begin{array}{l}\text { single EM } \\
\text { double EM }\end{array}$ & $\begin{array}{l}10 \\
1.4\end{array}$ & $\begin{array}{l}20 \\
0.2\end{array}$ \\
\hline
\end{tabular}

Upon a level-1 accept ( $50 \mathrm{kHz}$ for $20-\mathrm{GeV}$ threshold and longitudinal isolation $<0.1$ ):

1. The digitized information for the entire calorimeter is sent to an L2 buffer within a data collection network (DCN).

2. High zero-suppression is imposed $(1 \mathrm{GeV})$ on EM cells at full granularity, and this data is passed through the data collection network.

3. A switch is used to direct the event fragments from the output of the data collection network to a farm of processors.

4. An L2 algorithm calculates local transverse isolation using the highly zero-suppressed data and then sends result to gating logic where an L2 accept or reject is generated.

5. Upon an $\mathrm{L} 2$ accept, the full calorimeter with $100 \mathrm{MeV}$ (or low zerosuppression) is again passed through the same data collection network, switch, and processor farm for L3 processing.

Further details about such DAQ architectures can be found in References 10 and 11.

\section{Conclusions}

The $\mathrm{H} \rightarrow 2 \gamma$ is one of the most challenging processes for triggering at the SSC. No tracks are required, nor are multilepton signatures available. For the most part, the process requires only calorimeter information. The desire for sensitivity to low-mass Higgs searches imposes low thresholds in calorimetric triggering. In a detector like GEM, a simple level-1 trigger based on thresholds on coarse towers and longitudinal isolation drops the trigger rate (while retaining signal) to under $100 \mathrm{kHz}$. At this point, through judicious use of high zero-suppression, it is shown that L2 transverse isolation is still effective. The greatly reduced data volume allows one to consider a trigger/DAQ system based on low bandwidth components (no greater than $10 \mathrm{Mbyte} / \mathrm{s}$ needed). In fact, a system where the L2 and L3 algorithms are run in the same processor farm seems possible. A number of outstanding issues still need to be resolved: What about other triggers? What are the real $\mathrm{L} 2 / \mathrm{L} 3$ latencies? It is clear that triggering/DAQ are intimately intertwined, and much can be gained by recognizing this fact. 


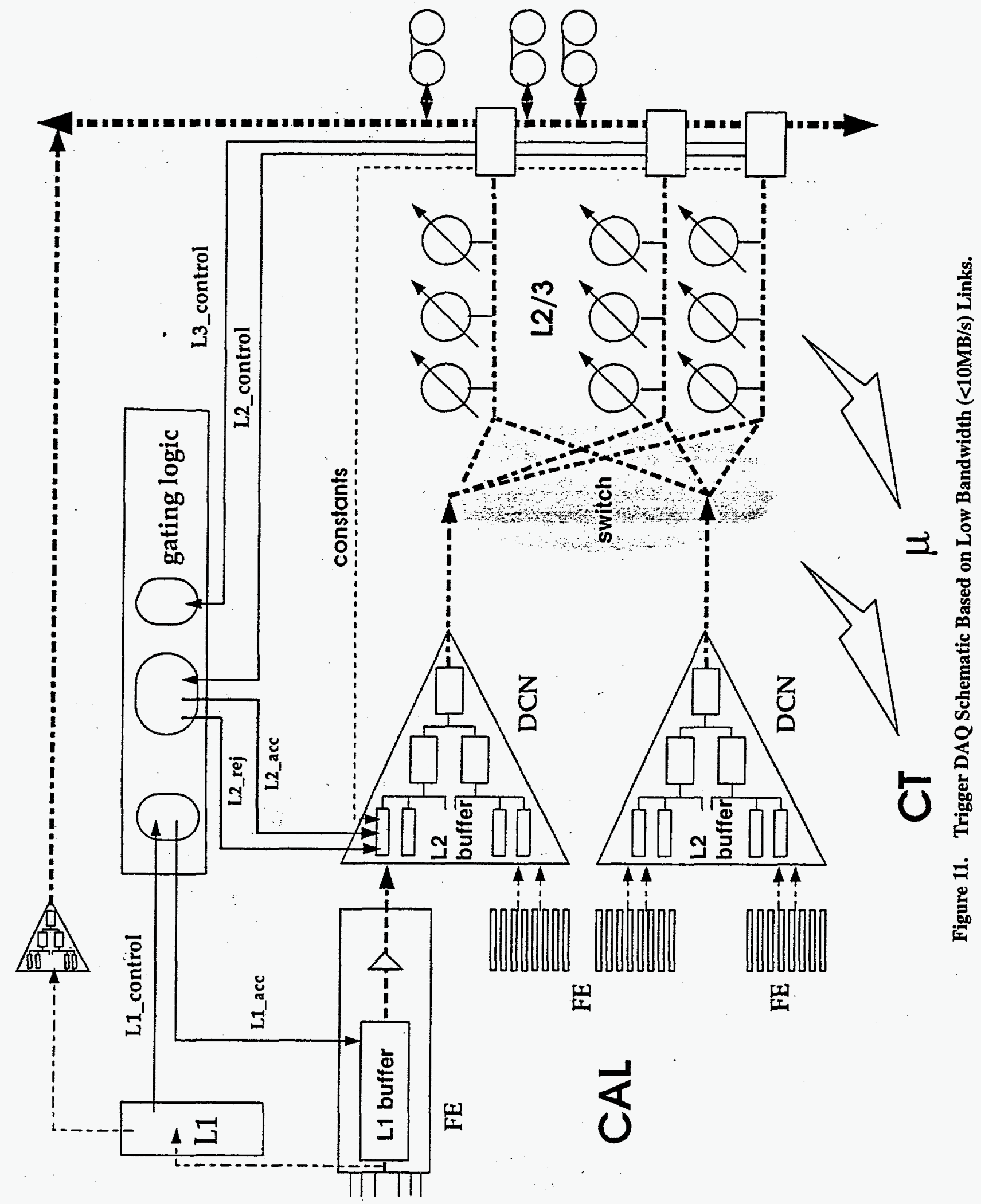




\section{References}

1. F. Gilman et al., Proceedings of Physics of the Superconducting Supercollider (Snowmass, 1986), p. 185.

2. D. M. Atwood et al., Proceedings of the Workshop on Experiments, Detectors, and Experimental Areas for the Supercollider (Berkeley, 1987), p. 728.

3. H. U. Bengtsson and T. Sjöstrand, in Proceedings of Physics of the Superconducting Supercollider (Snowmass, 1986), p. 311.

4. GEM Baseline 1, GEM TN-92-76 (1992).

5. R. Brun et al., GEANT3 documentation CERN DD/EE/84-1 (1987).

6. J. Freeman and A. Beretvas, in Proceedings of Physics of the Superconducting Supercollider (Snowmass, 1986), p. 482.

7. A. Bay et al., in Proceedings of High Energy Physics in the 1990s (Snowmass, 1988), p. 882.

8. J. Ranft and G. R. Stevenson, FLUKA86 Users Guide, CERN TIS-RP/168 (1986).

9. D. Marlow and M. Shaevitz, "GEM Triggering Transparencies," GEM Tucson 1992 meeting.

10. A. Booth et al., Simulation Studies of Data Acquisition Systems at the SSC, SSCL-SR-1148 (1992).

11. M. Botlo et al., Data Acquisition for Super Colliders, preprint for Como conference proceedings, to be published (1992). 